\title{
A contribuição da História das Ciências para formação de educadores do campo
}

\author{
Maricleide Pereira de Lima Mendes ${ }^{1}$, Jaqueline de Souza Pereira Grilo ${ }^{2}$ \\ ${ }^{1}$ Universidade Federal do Recôncavo da Bahia - UFRB. Centro de Ciência e Tecnologia em Energia e \\ Sustentabilidade (CETENS). Avenida Centenário, 697, Feira de Santana - BA. \\ Brasil. maricleide.mendes@ufrb.edu.br. ${ }^{2}$ Universidade Federal do Recôncavo da Bahia - UFRB.
}

RESUMO. O presente trabalho tem como objetivo analisar, sob a óptica da perspectiva crítico-dialética, aspectos da História das Ciências e a importância da abordagem externalista na formação de educadores do campo. A análise empreendida tomou como referência as atividades desenvolvidas no componente curricular História das Ciências de um curso de Licenciatura em Educação do Campo. Essas atividades permitiram explorar aspectos da Natureza da Ciência de maneira integrada com o contexto social, político, econômico, ético e científico dos sujeitos do campo. Os resultados indicam que atividades baseadas numa abordagem externalista possibilitam uma nova visão sobre a evolução dos conceitos da Ciência, contribuindo positivamente para o Ensino de Ciências na Educação do Campo.

Palavras-chave: Educação do Campo, História das Ciências, Formação de Professores. 


\title{
The contribution of the History of Science for teachers training in Rural Education
}

\begin{abstract}
The present work aims to analyze, from a criticaldialectical perspective, aspects of the History of Sciences and the importance of the externalist approach in the teachers training of rural education. The analysis undertaken took as a reference the activities developed in the curriculum component History of Sciences of a course of degree in Rural Education. These activities allowed exploring aspects of the Nature of Science in an integrated way with the social, political, economic, ethical and scientific context of the rural population. The results indicate that activities based on an externalist approach make possible a new vision on the evolution of the concepts of Science, contributing positively to the Teaching of Sciences in Rural Education.
\end{abstract}

Keywords: Rural Education, History of Science, Teachers Training. 


\title{
La contribución de la Historia De las Ciencias para la formación de profesores rurales
}

\begin{abstract}
RESUMEN. El presente trabajo tiene como objetivo analizar, desde la óptica de la perspectiva crítico-dialéctica, aspectos de la Historia de las Ciencias y la importancia del enfoque externo en la formación de profesores rurales. El análisis emprendido tomó como referencia las actividades desarrolladas en el componente curricular Historia de las Ciencias de un curso de Licenciatura en Educación del Campo. Estas actividades permitieron explorar aspectos de la Naturaleza de la Ciencia de manera integrada con el contexto social, político, económico, ético y científico de los sujetos rurales. Los resultados indican que las actividades basadas en un enfoque externo posibilitan una nueva visión sobre la evolución de los conceptos de la ciencia, contribuyendo positivamente a la enseñanza de las ciencias en la educación rural.
\end{abstract}

Palabras clave: Educación Rural, Historia de las Ciencias, Formación de profesores. 


\section{Introdução}

A inclusão da abordagem histórica no ensino de Ciências é defendida por muitos pesquisadores que atuam nessa área (Angotti \& Auth, 2001; Peduzzi, 2001; Nascimento, 2004). Sendo assim, um dos principais resultados que emerge dessas discussões é que a sua inserção pode desencadear melhorias para o ensino de Ciências. Neste trabalho, analisamos, sob a óptica da perspectiva crítico-dialética, aspectos da História das Ciências e a importância da abordagem externalista na formação de educadores do campo, com o objetivo de criar um diferencial que possibilite um ensino mais interessante e contextualizado para estudantes de um curso de Licenciatura em Educação do Campo.

A importância deste trabalho fica evidente quando, cada vez com maior frequência, há a necessidade de se conhecer a linguagem científica para compreender a situação da Ciência e da Tecnologia sob o ponto de vista das consequências sociais, econômicas, políticas, culturais e éticas.

$\mathrm{Na}$ busca de meios para contextualizar o ensino e mostrar o processo de transformação da Ciência, a abordagem histórica da Ciência tem sido indicada como uma estratégia didática que pode trazer benefícios em vários níveis. A pesquisa nesse sentido é ampla e conta com uma intensa bibliografia, nacional e internacional (Villani, Pacca \& Freitas, 2009; Forato, 2009). De modo geral, os argumentos para a utilização da História das Ciências são, entre outros, o fato de que: humaniza o conteúdo ensinado; favorece melhor compreensão dos conceitos científicos, pois os contextualiza e discute seus aspectos sociais, políticos e econômicos; ressalta o valor cultural da Ciência; enfatiza o caráter mutável do conhecimento científico; e permite uma melhor compreensão do método científico (Matthews, 1995; Höttecke \& Silva, 2011, Anunciação Neto \& Moradillo, 2014).

Para Scheid (2008), a inclusão da História da Ciência, como a história da construção do conhecimento, possibilita priorizar o aspecto dinâmico do saber científico. Permite, de acordo com Bachelard (1996), iluminar o passado pela luz do presente, pois traz à tona caminhos percorridos até se chegar à Ciência atual. Apoiando-nos em Scheid (2008), diremos que incluir a História da Ciência em um curso de formação de professores, que atuarão na Educação do Campo, significa fazer uma história essencialmente crítica da reconstrução da linha de desenvolvimento do saber científico; não é 
apenas contar os fatos ocorridos, restritos à descrição de nomes, datas e resultados.

Aqui defendemos o uso de uma abordagem crítica da História da Ciência que problematize como o processo de produção do conhecimento decorre de aspectos políticos, econômicos e culturais de uma determinada sociedade. Logo, não acontece de forma linear, podem ser transformados, modificados, alterados, pois não se tratam de verdades imutáveis.

A inclusão da História da Ciência em um curso de Licenciatura em Educação do Campo com habilitações em Ciências da Natureza e Matemática torna-se importante porque pode ser levada para a sala de aula a superação do realismo e do materialismo ingênuo, pois a mesma se apoia em uma racionalidade cada vez mais progressiva. Esses processos de rupturas com essas concepções anteriores abrem perspectivas inovadoras que se fundamentam em diversas estratégias didáticas no Ensino de Ciências. Tais inovações consideram a importância da compreensão histórica do conhecimento científico para superar algumas dificuldades que se apresentam no ensino, seja na Educação Básica ou Superior.

Uma perspectiva de ensino baseada na abordagem histórica visa à formação do indivíduo para além do ler, do escrever e do interpretar. Avança para a aquisição dos conhecimentos científicos e tecnológicos construídos pela humanidade no decorrer dos anos, conhecimento esse de grande importância na formação de professores.

Após esse preâmbulo sobre a importância da História da Ciência no ensino, expomos a seguir uma discussão sobre essa abordagem para a formação de educadores do campo. Nas seções seguintes são apresentadas a metodologia, a sequência didática implementada, os resultados e discussões e, por fim, as considerações finais.

\section{Importância da abordagem histórica na formação de educadores do campo}

A reflexão sobre o processo de formação de professores para a educação do campo tem suas bases construídas a partir de interesses do contexto sociopolítico das exigências colocadas pela realidade social, das finalidades da educação, do lugar que a educação ocupa nas políticas governamentais e das lutas travadas pelos movimentos sociais e sindicais.

Nesta perspectiva, acreditamos que se faz necessário uma reflexão sobre o ensino de Ciências para melhor compreensão da relação Ciência e sociedade, considerando as discussões atuais que defendem uma abordagem contextual e histórica do ensino na 
conjuntura da sociedade contemporânea, globalizada e tecnológica.

Rever o ensino na educação do campo incluindo em seus currículos o ponto de vista histórico dos conteúdos se torna essencial na formação de futuros professores, uma vez que com a inserção da abordagem histórica é possível humanizar as Ciências e aproximá-las dos interesses pessoais do estudante. Dos benefícios provenientes dessa medida estão à promoção, junto aos futuros professores, do desenvolvimento do pensamento crítico e a superação da falta de significados que marca boa parte dos conteúdos escolares e, consequentemente, os futuros professores passam a ter um melhor entendimento da estrutura das Ciências.

Hernandez-González \& Prieto Pérez (2000) defendem a introdução da História das Ciências desde a Educação Básica até o nível superior, sendo iniciada com um esclarecimento em torno do conceito de Ciência, compreendendo-a como uma criação humana. Segundo os autores, no nível superior, a História das Ciências, preservando o seu caráter interdisciplinar que inter-relaciona as ciências ditas duras (Matemática e Ciências Naturais) e as ciências humanas, deve contemplar os três grandes modelos de Ciência existentes ao longo da história: o antigo, o moderno e o contemporâneo. Entretanto, os autores chamam atenção para o fato de que os cursos de formação de professores precisam considerar a presença da História das Ciências, a fim de evitar a especialização deformante do conhecimento em parcelas, que divide e separa a figura do cientista humanista e do humanista científico.

Neste contexto, advogamos o uso da História da Ciência como um dos possíveis caminhos em um curso de Licenciatura em Educação do Campo, que pode fomentar uma formação mais significativa; por conseguinte, um ensino de Ciência na sua totalidade.

Opondo-se ao modelo de "educação rural" urbanocêntrico que historicamente imperou no Brasil, a Educação do Campo trata de uma educação "com os" e não "para os" sujeitos do campo. Uma educação que reflita a luta pela terra, pela Reforma Agrária, pelo direito ao trabalho, à cultura, à soberania alimentar, ao território. Segundo Pires (2012) a educação do campo reconhece a especificidade dos habitantes que vivem no campo e reafirma a legitimidade da luta por políticas públicas que garantam um projeto educativo em respeito à diversidade cultural.

Segundo Caldart (2002) a educação do campo deve se apresentar na perspectiva de educar os sujeitos do 
campo, para que assim eles possam se articular, se organizar e assumir a direção de seus destinos. O reconhecimento de que as pessoas que vivem no campo têm direito a uma educação diferenciada daquela oferecida a quem vive nas cidades ganhou força a partir da instituição, pelo Conselho Nacional de Educação, das Diretrizes Operacionais para a Educação Básica nas Escolas do Campo (Brasil, 2002). Esse reconhecimento ultrapassa a noção de espaço geográfico e compreende as necessidades culturais, os direitos sociais e a formação integral desses indivíduos (Brasil, 2002).

Segundo essas diretrizes, a educação deve abranger os processos formativos que se desenvolvem no contexto do sujeito, ou seja, na vida familiar, na convivência humana, no trabalho, nas instituições de ensino e pesquisa, nos movimentos sociais e organizações da sociedade civil e nas manifestações culturais.

Sendo assim, pensar a educação do campo requer uma ação políticopedagógica que rompa, dentre outras coisas, com a perspectiva dominante na formação de professores calcada numa concepção pedagógica de cunho idealista e de Ciência empírico-analítica. O método empírico-analítico é um método de observação utilizado para aprofundar o estudo desses fenômenos, podendo estabelecer leis através da conexão existente entre causa e efeito em um determinado contexto.

Partindo do pressuposto de que todas as pessoas possuem e podem produzir o conhecimento, acreditamos que os futuros professores precisam levar em consideração o contexto dos educandos e resgatá-los dentro da sala de aula num diálogo permanente com os saberes produzidos nas diferentes áreas de conhecimento. $\mathrm{O}$ processo educacional deve compreender que os sujeitos possuem história e concepções diversas. Neste sentido, esse processo deve considerar os aspectos da diversidade, os recursos disponíveis, as expectativas, os anseios e necessidades dos que vivem no campo (Arroyo, Caldart \& Molina, 2004).

Neste contexto, acreditamos que dentre as estratégias destinadas ao ensino em um curso de formação de professores para a educação do campo, a abordagem histórica pode proporcionar uma articulação do conhecimento empírico popular com o conhecimento científico. A interação dialógica, que é estabelecida quando se utiliza a abordagem histórica na sala de aula, poderá despertar o interesse dos alunos e, dessa forma, melhorar a compreensão de conceitos e conteúdo dessa Ciência. 
$\mathrm{Na}$ educação, tanto urbana, quanto do campo, a aprendizagem de conteúdos de Ciências é visto com dificuldade pelos estudantes, pois eles dificilmente conseguem relacioná-los com fatos de seu cotidiano. Para eles, esses conteúdos estão deslocados da realidade em que vivem e sendo assim, não há necessidade de aprendê-los. Para que este cenário mude, é necessária a intervenção do professor, que deverá integrar os conteúdos de Ciências ao contexto social do estudante, fazendo assim com que eles percebam que muitos conceitos estudados, por exemplo, na Química ou na Matemática, são importantes para que eles entendam e participem ativamente da sociedade em que vivem.

Neste sentido, D’Ambrósio (1994) apresenta-nos a concepção de etnociência enquanto estudo de fenômenos científicos e, por extensão, tecnológicos numa relação direta com a formação social, econômica e cultural, por meio da articulação entre os saberes. No ensino de química, a inserção de conhecimentos tradicionais no currículo é uma ideia nova e incipiente; e a perspectiva mais próxima e amplamente disseminada refere-se à inserção do conhecimento popular, trazidas por Chassot (2006) em sua obra "A Alfabetização Científica: questões e desafios para a educação”. Acreditamos que a etnociência/etnoquímica procura entender os processos de geração e construção de conhecimentos no fazer Ciência de cada grupo, na manutenção de seus valores e práticas culturais, sociais, religiosas, profissionais, possibilitando uma maior interação entre os mesmos.

Diferente do que ocorre com a etnoquímica, o conceito de etnomatemática é amplamente difundido na área de Educação Matemática que tem sua agenda de pesquisa consolidada, principalmente, pelos estudos desenvolvidos por D’Ambrósio (1996; 1998; 2002), Knijinik (1993) e Gerdes (1991). Com base nesses estudos, a área tem compreendido a etnomatemática como a arte ou a técnica de explicar, de conhecer, de entender, nos diversos contextos culturais, a matemática praticada por grupos culturais distintos. A análise recai sobre as práticas matemáticas praticadas fora da escola, e como elas podem contribuir para o desenvolvimento da Matemática prevista nos currículos escolares.

O fato é que, segundo Gil-Perez et al. (2001), ainda existe um predomínio de concepção de Ciência baseada na ideia cumulativa e linear de teorias e leis. Sem conhecer o contexto em que esses conhecimentos surgiram, os estudantes concebem ideias de verdades universais e da impossibilidade de erros e incertezas na 
Ciência. Essas concepções errôneas sobre a natureza da Ciência, por parte dos estudantes, são resultados de concepções também equivocadas dos professores (Abd-El-Khalick \& Lederman, 2000; GilPérez et al., 2001).

Portanto, se queremos formar professores capazes de discutir não só a Ciência, mas também a natureza da Ciência, e se queremos na mesma linha estudantes conscientes do mundo em que vivem e aptos a compreendê-lo, é necessário que outras abordagens sejam realizadas tanto na formação de professores, quanto em sala de aula (Moura \& Silva, 2007).

Este trabalho abarca uma perspectiva de história que é crítico-dialética. Ao assumirmos essa perspectiva, estamos defendendo que é na produção material da nossa existência e nas relações sociais de produção que o homem se humaniza, se educa, se qualifica, compreende e transforma as circunstâncias em que está inserido. A utilização da abordagem histórica no ensino de Ciências, que assume uma perspectiva crítico-dialética, tenta articular questões internalistas da Ciência a questão epistemológica e a questões externalistas, que são os fatores sociais, principalmente, econômico, político e ético.

Segundo Martins (2007, p. 115):
A História e Filosofia da Ciência surgem como uma necessidade formativa do professor, na medida em que pode contribuir para evitar: visões distorcidas sobre o fazer científico; permitir uma compreensão mais refinada dos diversos aspectos envolvendo o processo de ensino aprendizagem da Ciência; proporcionar uma intervenção mais qualificada em sala de aula.

Uma abordagem histórica no ensino pode viabilizar a discussão de aspectos sócio-históricos em sala de aula, uma vez que oferece um panorama mais amplo dos fatos históricos e da construção e da natureza de Ciência. Neste contexto, acreditamos que em um curso de formação de professores, no nosso caso, formação de professores para a educação do campo, o objetivo da abordagem histórica no ensino das Ciências não visa descrever a história de maneira linear e acumulativa, mas propiciar uma análise crítica da construção e apropriação do conhecimento científico pelas diversas culturas e salientar que este conhecimento está sujeito a transformações.

Nesta prática didática, ao utilizarmos essa abordagem estaremos criando condições de aprendizagem a partir de uma prática dialógica que envolve argumentações, reflexões, ponderações e explicações. Assim, por meio dessas atividades argumentativas, além de tomarem consciência de suas próprias 
ideias, os discentes fazem uso de uma nova linguagem com características da cultura científica. A forma com que estes passam a explicar/argumentar um determinado fenômeno, a linguagem e os exemplos por eles utilizados nessa argumentação, os coloca em contato com características de construção coletiva de novos conceitos e demonstram o caráter provisório dos mesmos.

Bernal (1990) aponta que nos estudos da História da Ciência existem algumas tendências teóricas, sendo que as principais são a internalista e a externalista. Dessa maneira, ao levar a História da Ciência para a sala de aula, é possível discutir diferentes aspectos históricos e sociais ligados à construção do conhecimento, proporcionando um entendimento mais amplo e com mais significados.

Neste contexto, a História da Ciência pode funcionar como um importante instrumento para articular esses acontecimentos, ressaltando assim o papel da Ciência como parte da cultura humana acumulada ao longo dos séculos. Uma abordagem, nestes moldes, favorece uma formação adequada do professor.

$\mathrm{Na}$ perspectiva crítico-dialética, a história é concebida a partir do desenvolvimento material e da determinação das condições materiais da existência humana. Abordar dialeticamente a História das Ciências no ensino é entender a aprendizagem como reflexo de um processo histórico que está suscetível a transformações. Neste sentido, o uso da História das Ciências num curso de formação de professores do campo torna-se uma proposta sólida para o ensino de aspectos da natureza da Ciência.

Diante disso, desenvolvemos este estudo tomando a perspectiva críticodialética da Ciência como aporte teórico, com o intuito de identificar princípios norteadores para uma abordagem histórica da Ciência na sua totalidade. Na próxima seção, apresentaremos uma discussão sobre a importância da abordagem histórica na formação de educadores do campo. Posteriormente, descreveremos os procedimentos utilizados durante as aulas do componente curricular História da Ciência, a análise e discussão dos resultados e, por fim, algumas considerações acerca desses resultados.

\section{Metodologia}

A investigação teve como participantes 91 estudantes de duas turmas do $4^{\circ}$ período de um Curso de Licenciatura em Educação do Campo com habilitações em Ciências da Natureza e Matemática, da Universidade Federal do Recôncavo da 
Bahia, que estavam matriculados no componente curricular História das Ciências.

O referido curso tem seu currículo baseado na Pedagogia da Alternância, que é caracterizada por dois momentos, sendo a parte teórico-pedagógica desenvolvida na universidade, chamada de Tempo Universidade (TU); e outra parte prática, denominada de Tempo Comunidade (TC), no qual os estudantes estabelecem a relação entre o teórico-prático a partir de uma concepção de práxis, desenvolvendo atividades de pesquisa e extensão em suas respectivas comunidades. As atividades ora apresentadas foram desenvolvidas no TU e no TC, tendo a primeira autora como orientadora das atividades.

No plano de ensino proposto para o componente curricular História das Ciências, procuramos evidenciar o entendimento da natureza histórica, social e cultural do conhecimento científico. Assim, este espaço curricular não apenas abordou elementos da historiografia da Ciência, mas problematizou o seu papel no ensino e, em particular, no ensino de Ciências para a educação do campo. Foram realizadas atividades que propõem um ensino de Ciências articulado à dimensão cultural e social do conhecimento científico.
A modalidade de pesquisa adotada foi a ação pesquisada, que é uma forma de investigação-ação, termo genérico usado para qualquer processo que siga um ciclo no qual se aprimora a prática pela oscilação sistemática entre agir no campo da prática e investigar a respeito dela (Tripp, 2005). Os efeitos da ação foram avaliados por meio da técnica de observação, onde utilizamos anotações como instrumento de coleta de dados, articulada a aplicação de questionários. $\mathrm{O}$ questionário continha 05 (cinco) questões abertas que versaram sobre: $1-a$ importância de se conhecer a Natureza da Ciência; 2 - a relação entre os aspectos históricos e o presente; 3 - a importância de se trabalhar a História das Ciências na sala de aula; 4 - a transitoriedade do conhecimento científico e sua aproximação com a realidade; 5 - a imagem do cientista.

A dinâmica de trabalho com os estudantes teve início com a divisão da turma em grupos de cinco alunos para a discussão de textos. A cada semana, um grupo apresentava um seminário sobre o tema escolhido, seguido por uma discussão aberta a todos os grupos que haviam previamente lido o texto em questão. Os temas da História da Ciência discutidos foram: a importância da abordagem histórica num curso de formação de professores para a educação do campo; 
origens das atividades científicas; a Ciência na Antiguidade; a Ciência medieval; o nascimento da Ciência Moderna; a Ciência clássica do século XIX; a Ciência do século XX e as perspectivas científicas para o futuro da humanidade, além da relação entre Ciência e aspectos sócios históricos.

Após a apresentação dos seminários os estudantes prepararam peças teatrais que abordaram os temas apresentados nos seminários articulando esses temas ao ensino de Ciências nas escolas do campo. Outras atividades que também possibilitaram interessantes abordagens para o aprofundamento das discussões realizadas em sala de aula foram desenvolvidas no TC (Quadro 1).

\section{Quadro 1 - Atividades desenvolvidas no Tempo Comunidade}

\begin{tabular}{|c|c|}
\hline Atividade 1 & Atividade 2 \\
\hline $\begin{array}{l}\text { Cada grupo elaborou uma análise crítica } \\
\text { sobre o filme "O Nome da Rosa", obra } \\
\text { homônima de Umberto Eco e dirigido por } \\
\text { Jean-Jacques Annaud, que constrói um } \\
\text { retrato bastante elaborado da forma como } \\
\text { o conhecimento era concebido e } \\
\text { transmitido na Idade Média e das } \\
\text { dificuldades para romper estes cânones. } \\
\text { Para isso, foi feita uma análise sócio } \\
\text { histórica do período relatado no filme. }\end{array}$ & $\begin{array}{l}\text { Depois de realizar a síntese do filme e } \\
\text { com base da leitura do artigo de } \\
\text { Anunciação Neto \& Moradillo (2014) os } \\
\text { estudantes elaboraram uma ferramenta } \\
\text { didática como atividade final (cartilha } \\
\text { educativa ou uma oficina). }\end{array}$ \\
\hline
\end{tabular}

Fonte: Elaborada pelas autoras.

\section{A sequência didática}

A sequência didática desenvolvida iniciou com uma roda de conversa sobre os tópicos propostos abordando a importância do estudo da História das Ciências e suas implicações no processo de ensino e aprendizagem; desenvolvimento das Ciências modernas; olhar para a História: caminho para a compreensão da Ciência; a Ciência moderna; bases filosóficas da
Ciência moderna; modelos que emergiram da revolução Científica e aspectos sociais e culturais das Ciências na modernidade. Após alguns questionamentos sobre os temas abordados na roda de conversa, a turma foi dividida em grupos para serem trabalhados dois textos: texto 1 - "A importância do estudo da História das Ciências" de José Maria Filardo Bassalo e texto 2 - "Robert Boyle no contexto da transição para a Ciência moderna: 
elementos para uma análise sóciohistórica" de Bárbara Carine Pinheiro da Anunciação; Hélio da Silva Messeder Neto e Edilson Fortuna de Moradillo. Esses textos foram escolhidos por tratarem dos episódios históricos que escolhemos como objeto de estudo. Foi proposto então aos alunos que lessem os textos, identificando o que seria relevante, no que concerne a importância de se fazer uma abordagem histórica (grupos A e B) e como se deu o desenvolvimento da Ciência na transição do mundo feudal ao mundo do capital, levando em consideração a transição da Ciência medieval para a Ciência moderna (grupos C, D e E), e que trouxessem para o próximo encontro, suas colocações e discussões sobre os textos.

No segundo encontro iniciamos nossas atividades com a proposta de que os grupos deveriam apresentar oralmente as respostas dadas aos questionamentos realizados no primeiro encontro. Neste sentido, a fim de dinamizar a participação dos alunos e viabilizar a apresentação dos grupos, realizamos uma oficina pedagógica para a confecção de cartazes que deveriam utilizar na apresentação. Após os debates, com auxílio do projetor de slides, apresentamos aos alunos um estudo sobre a Natureza da Ciência, mostrando o desenvolvimento científico da humanidade desde os primórdios da civilização até os dias de hoje.

Dando prosseguimento à sequência, desenvolvemos uma segunda oficina com o grupo de alunos. Iniciamos com uma proposta de criarem uma dramatização do que estudaram e articulassem com o ensino da História das Ciências, para a educação do campo. Neste momento, eles tiveram a liberdade de escolher qualquer episódio histórico, para a apresentação.

No último dia, desenvolvemos uma atividade de escrita e pedimos que todos os alunos nos apresentassem, individualmente, suas ideias acerca do que fora discutido em sala de aula. Essas ideias deveriam vir relatadas na forma de uma resenha descritiva. Os alunos aqui tiveram a liberdade de escolher o texto para fazer a resenha descritiva, independente de terem trabalhado com o texto 1 ou texto 2 .

Para finalizarmos o trabalho no tempo universidade, aplicamos um questionário, no qual procuramos resgatar conceitos que haviam sido trabalhados nas aulas anteriores, bem como avaliarmos o nível de compreensão dos alunos acerca da compreensão da Ciência como uma construção humana.

No tempo comunidade foi pedido que os estudantes desenvolvessem as duas atividades que foram apresentadas no Quadro 1. 


\section{Resultados e discussões}

Nesta seção, apresentamos os resultados mais significativos obtidos nas duas oficinas: rodas de conversa e dramatizações. Os grupos foram formados por 08 (oito) discentes e as apresentações foram viabilizadas a partir da confecção de cartazes ou apresentação de seminários ou dramatizações.

As trocas de informações foram valiosas e pertinentes, pois entendemos que os conhecimentos, ideias e conceitos trazidos pelos discentes são importantes para que haja uma aprendizagem prazerosa. As colocações e discussões possibilitaram um excelente exercício de prática argumentativa, pois trouxe para a sala de aula um contexto de interações discursivas, levando-os a adquirirem competências para defender e justificar suas ideias e posições.

O relato apresentado a seguir traduz as ideias construídas, por um dos grupos sobre a importância de se trabalhar com a História da Ciência, numa abordagem externalista:

Cada fase compreendida neste trabalho nos permitiu refletir sobre a formação humana, a relação histórica do homem com a natureza e a centralidade do poder como uma forma de marginalização dos demais sujeitos. (Trecho do relatório do Grupo 2).
O que mais chamou atenção foi o trabalho em conjunto desenvolvido pelos discentes, pois os mesmos mostraram uma compreensão sobre a importância da abordagem histórica na sua formação como também a importância dessa abordagem no fazer pedagógico do professor que irá atuar na Educação do Campo.

Outro ponto que ficou evidente foi o fato deles perceberem que a construção da Histórica da Ciência e sua evolução não ocorre de maneira linear. Um dos grupos, na roda de conversa, destacou a importância da construção da cartilha, como segue:

A construção da cartilha contribuiu para o conhecimento sócio-histórico do grupo sobre a transição para a Ciência moderna ... [é preciso] socializar esse tema para que cada vez mais pessoas possam entender o processo de evolução da Ciência. (Trecho do relatório do Grupo 1).

Durante as apresentações das dramatizações, os estudantes trouxeram abordagens que dialogavam com uma visão de Ciência não linear e como essa abordagem poderia ser feita nas escolas do campo. Trazendo à tona reflexões a respeito de questões éticas importantes relacionadas à Ciência, à sua história e às controvérsias científicas existentes em diferentes períodos históricos. Com essa atividade, percebemos que os estudantes 
começaram a manifestar maior segurança em seus posicionamentos, como ilustra os trechos abaixo:

Este estudo nos possibilitou compreender que se faz necessário estabelecer um processo de investigação mais profundo, para desconstruir conceitos historicamente apreendidos...e reconstruir um novo pensar a evolução da Ciência. (Trecho do relatório do Grupo 5).

Realizar esta atividade é reconstruir a própria vida... Entender as relações entre Ciência, religião e história. (Trecho do relatório do Grupo 3).

A análise do contexto sócio histórico de determinado período da história, significa levar em consideração os aspectos lógicos e históricos que deram sustentação, naquele período, as seguintes dimensões filosóficas: modo de produzir bens materiais (o complexo econômico é seu fundamento), modo de produzir valores sociais (os complexos da ética e da política são o seu fundamento) e modo de produzir conhecimento (o complexo da teoria do conhecimento - as questões ontológicas e epistemológicas - é o seu fundamento), e encontrar o momento predominante de cada período histórico.

\section{Considerações finais}

Nas atividades desenvolvidas no componente curricular História da Ciência, os estudantes acompanharam desenvolvimento científico da humanidade desde as antigas civilizações até os dias de hoje. Neste passeio histórico, em vários momentos, estudaram como os homens se relacionam com o conhecimento construído historicamente nos diversos momentos históricos. Ao longo desse processo, perceberam e compreenderam que a Ciência pode ser estudada e aprendida de maneira integrada, incluída em um contexto social, político, econômico, ético e científico, de maneira não linear.

A avaliação das ações desenvolvidas foi explicitada nos depoimentos e em relatos que apareceram na cartilha. Analisando os relatos dos estudantes em formação, percebemos que os mesmos passaram a compreender que a construção histórica da Ciência está relacionada ao contexto histórico-social de cada etapa do desenvolvimento científico, bem como os interesses políticos, econômicos e religiosos envolvidos no processo, ou seja, passaram a ter uma visão mais externalista da Ciência.

Percebemos também que os estudantes e futuros professores passaram a entender que o desenvolvimento da Ciência não ocorre de forma linear. Ocorreu também uma mudança na visão tradicional que todos têm do cientista, a visão ingênua de que o cientista é um 
gênio. Os mesmos compreenderam que os cientistas são pesquisadores que participam do desenvolvimento de uma sociedade, em determinada época, por meio da Ciência. Isso possibilitou uma articulação com a tecnologia, estudo dos fenômenos da natureza por meio de experimentação e construção histórica.

Os relatos apontaram uma conscientização dos estudantes sobre a importância da contextualização histórica das Ciências e as possibilidades da História da Ciência como instrumento pedagógico para o trabalho em sala de aula. Os relatos indicaram ainda que os futuros educadores do campo almejam um ensino diferente do tradicional, no qual seja possível construir o conhecimento de forma compartilhada com os alunos, por meio de debates, pesquisas e com autonomia de pensamento, distanciando-se do ensino tradicional propedêutico e acrítico.

\section{Referências}

Abd-El-Khalick, F., \& Lederman, N. G. (2000). Improving science teachers' conceptions of the nature of science: a critical review of the literature. International Journal of Science Education, 22(7), 665-701.

Arroyo, M. G., Caldart, R. S., \& Molina, M. C. (Orgs.) (2004). Por uma Educação do Campo. Petrópolis: Vozes.
Arroyo, M., \& Fernandes, B. M. (1999). A Educação Básica e o Movimento Social do Campo. Brasília. DF: Articulação Nacional Por Uma Educação Básica do Campo.

Angotti, J. A. P., \& Auth, M. A. (2001). Ciência e Tecnologia: Implicações sociais e o papel da educação. Ciência \& Educação, 7(1), 15-27.

Anunciação, B. C. P., Messeder-Neto, H. S., \& Moradillo, E. F. (2014). Robert Boyle no contexto da transição para a ciência moderna: elementos para uma análise sócio-histórica. Ideação, 1, 165192.

Bachelard, G. (1996). A formação do espírito científico: contribuição para uma psicanálise do conhecimento. Rio de Janeiro: Contraponto.

Bassalo, J. M. F. (1992). A importância do estuda da História das Ciências. Revista da SBHC, 8, 57-66.

Bernal, J. D. (1975). Ciência na história. Lisboa: Livros Horizonte, 1.

Brasil. (1998). Secretaria de Educação Média e Tecnologia. Parâmetros Curriculares Nacionais: terceiro e quarto ciclos do ensino fundamental - Ciências Naturais. Brasília. MEC/SEMTEC.

Brasil. (2002). Diretrizes Operacionais para a Educação Básica nas Escolas do Campo. Brasília: MEC/SECAD.

Caldart, R. S. (2002). Por uma Educação do Campo: traços de uma identidade em construção. In Kolling, E. J., Cerioli, P. R., \& Caldart, R. S. (Orgs.). Articulação Nacional Por uma Educação do Campo. Brasília-DF.

Chassot, A. (2006). Alfabetização científica: questões e desafios para a educação. Ijuí: Ed. Unijuí. 
D’Ambrósio, U. (1994). A Etnomatemática no processo de construção de uma escola indígena. Em Aberto, 14(63), 92-99.

D’Ambrósio, U. (1998). Etnomatemática. São Paulo: Ática.

D’Ambrósio, U. (1996). Educação Matemática: da teoria à prática. Campinas, São Paulo: Papirus.

D’Ambrósio, U. (2002). Etnomatemática. Elo entre as tradições e a modernidade. Belo Horizonte: Autêntica.

Forato, T. C. M. (2009). A Natureza da Ciência como Saber Escolar: um estudo de caso a partir da história da luz. (Tese de Doutorado). Universidade de São Paulo, São Paulo.

Gerdes, P. (1991). Etnomatemática: Cultura, Matemática, Educação. Maputo: Moçambique.

Hernández-González, M., \& Prieto-Pérez, J. L. (2000). Un currículo para el estudio de la Historia de la Ciencia en secundaria (la experiencia del seminario Orotava de Historia de la Ciencia). Enseñanza de las Ciencias, 1(18), 105-112.

Pérez, D. G., Montoro, I. F., Alís, J. C., Cachapuz, A., \& Praia, J. (2001). Para uma imagem não deformada do trabalho científico. Ciência \& Educação, 7(2), 125153.

Hage, S. M. (2006). Movimentos Sociais do Campo e a afirmação do direito à educação: pautando o debate sobre as escolas multisseriadas na Amazônia paraense. Revista Brasileira de Estudos Pedagógicos, 217, 302-312.

Höttecke, D. (2000). Wow and what can we learn from replicating historical experiments? A case study. Science \& Education, 9, 343-362.
Knijnik, G. (1993). O saber acadêmico e o saber popular na luta pela terra. Educação Matemática em Revista, 1, 5-11.

Martins, A. F. P. (2007). História e Filosofia da Ciência no ensino: há muitas pedras nesse caminho. Caderno Brasileiro do Ensino de Física, 24(1), 112-131.

Moura, B. A., \& Silva, C. C. (2007) A Óptica Newtoniana No Século XVIII: O Que Podemos Aprender com esse Episódio? In VI Encontro Nacional de Pesquisa em Educação em Ciências - SC, Florianópolis.

Nascimento, V. B. (2004) A natureza do conhecimento científico e o ensino de ciências. In Carvalho, A. M. P. C. (Org.). Ensino de Ciências: unindo a pesquisa e a prática (pp. 35-57). São Paulo: Pioneira Thomson Learning.

Peduzzi, L. O. Q. (2001). Sobre a Utilização Didática da História da Ciência. In Pietrocola, M. (Org.). Ensino de física: conteúdo e epistemologia numa concepção integradora (pp. 151-170.). Florianópolis: Ed. da UFSC.

Scheid, M. N. J. (2008). Contribuições do cinema na formação inicial de professores de Ciências Biológicas. Vivências: revista Eletrônica da URI, 6(4), 15-21.

Tripp, D. (2005). Pesquisa-ação: uma introdução metodológica. Educação $e$ Pesquisa, 31(3), 443-466.

Villani, A., Pacca, J. L. A., \& Freitas, D. (2008). Science teacher education in Brazil: 1950-2000. Science \& Education, $18,125-148$.

Pires, A. M. (2012). Educação do Campo como direito humano. São Paulo: Cortez. 
Recebido em: 23/05/2017

Aprovado em: 05/06/2017

Publicado em: 11/09/2017

\section{Como citar este artigo / How to cite this article / Como citar este artículo:}

APA:

Mendes, M. P. L., \& Grilo, J. S. P. (2017). A contribuição da História das Ciências para a formação de educadores do campo. Rev. Bras. Educ. Camp., 2(2), 632-649. DOI: http://dx.doi.org/10.20873/uft.2525-

4863.2017v2n2p632

ABNT:

MENDES, M. P. L.; GRILO, J. S. P. A contribuição da História das Ciências para a formação de educadores do campo. Rev. Bras. Educ. Camp., Tocantinópolis, v. 2, n. 2, p. 632-649, 2017. DOI: http://dx.doi.org/10.20873/uft.2525-

4863.2017v2n2p632

\section{ORCID}

Maricleide Pereira de Lima Mendes

http://orcid.org/0000-0001-6055-7415

Jaqueline de Souza Pereira Grilo

iD http://orcid.org/0000-0002-0408-047X 